INDO GLOBAL JOURNAL OF

PHARMACEUTICAL SCIENCES

ISSN 2249- 1023

\title{
Harmful Effects of Organophosphate Pesticides: A Study using Yeast Model System
}

\author{
Pratibha Chauhan, S. Krishna Sundari * \\ Department of Biotechnology, Jaypee Institute of Information Technology, Noida-201309, UP, India
}

Address for Correspondance: S. Krishna Sundari, Krishna.sundari@jiit.ac.in ; cpratibha91@gmail.com

\section{Keywords}

Pesticides; Chronic Health Problems; Reactive Oxygen Species; Oxidative Stress; Apoptosis.
ABSTRACT: Pesticides have greatly contributed to the increase of yields in the agriculture sector by controlling pests and diseases and also in the prevention of the insect-borne diseases in the human health sector. However, the continuous use of pesticides leads to significant consequences not only to public health but also to food quality resulting in an impact on the environment and the development of pest resistance. Pesticides being used in agricultural field are released into the environment and come into human contact directly or indirectly and results in acute and chronic health problems such as increasing incidence of cancer, chronic kidney diseases, suppression of the immune system, sterility among males and females, endocrine disorders, neurological and behavioral disorders, especially among children. Yeast has been use by many researchers to study the mechanisms involved behind the toxic effects of various pesticides as there is a high degree of evolutionary convergence between the stress response pathways of yeast and higher eukaryotes. In our study, we also used yeast as a model organism to study the mechanism behind the toxic effect of pesticides such as the generation of reactive oxygen species (ROS) and oxidative stress due to which the inhibition of yeast cells growth, decrease in the number of viable cells and apoptosis of affected cells was observed. (C) 2016 iGlobal Research and Publishing Foundation. All rights reserved.

Conference Proceedings: International Conference on Advances in Plant and Microbial Biotechnology (PMB2017); JIIT, Noida: February 02-04, 2017

Indo Global Journal of Pharmaceutical Sciences( ISSN 22491023 ; CODEN- IGJPAI; NLM ID: 101610675) indexed and abstracted in EMBASE(Elsevier), SCIRUS(Elsevier),CABI, CAB Abstracts, Chemical Abstract Services(CAS), American Chemical Society(ACS), Index Copernicus, EBSCO, DOAJ, Google Scholar and many more. For further details, visit http://iglobaljournal.com 